\title{
Hydrological, Geochemical and Geophysical Changes Related to Earthquakes and Slow-Slip Events: Introduction
}

\author{
$\mathrm{CHI}_{-} \mathrm{Yu}_{\mathrm{U}} \mathrm{King}^{1}$ and Michael Manga ${ }^{2}$
}

It has been documented for thousands of years that earthquakes and other tectonic processes have hydrological effects. Fault ruptures and the seismic waves they produce deform the crust, so it is expected that crustal fluids respond. The magnitude of the hydrological response can be very large because small stresses can be greatly amplified as changes in water pressure. This is also the premise behind searching for earthquake precursors; the very small hypothesized strains leading up to rupture might have hydrological, geochemical or geophysical manifestations. The magnitude and spatial and temporal patterns of reported changes are not always straightforward to explain and hence, remain the subject of active research.

Ten of the 11 papers collected in this special issue present new observations and explanations. They include various earthquake-related hydrological, geochemical and geophysical changes observed in several seismic regions of Japan, Taiwan, Baja California in Mexico, and China mainland. The majority (seven) of these papers are contributed from China, including a laboratory study on rock mechanics and a brief overview of the Chinese efforts in earthquake prediction research over the past half-century. Similar collections of papers were published earlier, and they include King (1980, 1981, 1984, 1986), Dubois (1995) and Perez et al. (2006, 2007, 2008). For a book providing a review of the interactions between earthquakes and water, see Wang and Manga (2010);

1 Earthquake-Prediction Research Inc, Los Altos, CA, USA. E-mail: chiyuking@gmail.com

2 Department of Earth and Planetary Science, University of California, Berkeley, CA 94720, USA. E-mail: manga@seismo.berkeley.edu a number of other texts provide overviews of how fluid are affected by mechanical deformation of rocks (e.g., Wang 2000; Coussy 2004; Segall 2010).

The most important goal of studying the various earthquake-related changes is to find possible earthquake precursors that might be useful for earthquake forecasting. However, because of the complexity of the real Earth with many confounding environmental and geological variables, many claimed precursory signals turned out not to be precursors to earthquakes. During the past two decades, the mainstream opinion has been that earthquakes are not predictable and the pursuit of prediction should not be continued (Geller et al. 1997). The discovery of slow-slip events provides renewed hope for identifying and understanding precursory signals.

King (2018) describes the characteristics of a sensitive well in Japan that showed many co-seismic and several pre-earthquake water level changes, some of which may originate from slow-slip events. The well is sensitive because it taps a highly permeable aquifer connected to one side of a nearby fault consisting of an impermeable gouge layer sandwiched between two fractured walls and subject to a large hydraulic gradient.

Streamflow changes after earthquakes are some of the most dramatic hydrological responses to earthquakes. Liu et al. (2017) report streamflow changes at 23 gauges in central Taiwan after the $1999 \mathrm{M}_{\mathrm{W}} 7.6$ Chi-Chi earthquake. Post-earthquake increases were recorded at 22 gauges and are attributed to rock fracturing by seismic shaking as well as pore pressure rise due to compressive strain. A large post-earthquake decrease was recorded immediately after the earthquake at the gauge located $4 \mathrm{~km}$ from the epicenter on the hanging wall of the fault. They attribute 
this decrease to infiltration through the streambed due to a co-seismic decrease in pore pressure induced by co-seismic crustal extension. King and Chia (2017) showed that this 8-month-long streamflow decrease was preceded by a comparable increase starting 4 days before the earthquake. Further, they document a pre-earthquake groundwater level change at a well $1.5 \mathrm{~km}$ from the surface trace of the fault. Since both the stream and the well are on the hanging wall, they attribute the pre-earthquake streamflow increase to gravity-driven groundwater discharge into the creek due to crustal buckling, and the water level anomaly to shallow slow-slip events triggered by the postearthquake downward water flow.

The most abundant data come from wells. Sun et al. (2017) use the Molchan (1990) error diagram test to interpret data from a well in China, and conclude that the well is somewhat predictive of regional earthquakes, with a prediction gain of a factor of two within 30 days of water level anomalies. Ma et al. (2017) document changes in water level after the 2008 Wenchuan earthquake and conclude that changes in permeability can explain the observed water level changes. Zhang et al. (2017) similarly show that earthquake-induced changes in permeability can explain changes in water level near the Three Gorges, China, after that same earthquake. Sarychikhina et al. (2018) compare groundwater level and temperature changes with ground deformation recorded before and after a magnitude 5.4 earthquake and its foreshock and aftershocks in the Mexicali Valley of Baja California, Mexico. They attribute the co-seismic water level changes to static volumetric strains caused by the main shock, except in one well, where the water level change may have been affected also by a triggered slip event on a nearby fault. Some of the co-seismic temperature changes are explained by convection and mixing of groundwater by seismic shaking. These changes together with some gradual pre-earthquake changes are explainable by the dilatancy-diffusion theory, or possibly by assuming the occurrence of a slow-slip event and/or fault permeability changes.

Wang et al. (2018a, b) studied the stress evolution during a 10-year period before the $2008 \mathrm{M}_{\mathrm{s}} 8.0$ Wenchuan earthquake around the seismogenic fault using the method of cataclastic analysis (Rebetsky
2009). They found some significant stress changes before the earthquake.

Shi et al. (2017) interpret groundwater and animal behavior anomalies along a fault zone in the Xichang area, southwestern Sichuan Province, China, from May to June 2002, after which no major earthquake occurred. A comparison with geodetic data and seismicity suggests that the anomalies may be the result of increased tectonic activity in the SichuanYunnan block.

Ren et al. (2017) report a laboratory rock mechanics experiment in which a series of stick-slip events were generated along a precut planar strike slip fault in a granodiorite block under bi-axial compression. Temperature increased prior to each slip event in sections of the fault plane due to partial sliding, but decreased inside the rock itself due to stress relaxation. The regions of increased temperatures expanded rapidly immediately prior to each stick-slip event.

In the absence of quality long-term records, it is not possible to establish the reliability of reported precursory signals. Wang et al. (2018a, b) provide brief overview of the extensive effort since 1966 to monitor hydrological and geochemical changes for the purpose of earthquake prediction in China. Since the results of previous studies using this data were published mostly in Chinese, this overview should help those who cannot read Chinese to understand what data were collected and what has been learned to date.

The papers in this special issue also make clear that to mount an effective effort to search for, identify, and then understand precursory signals, it is important to recognize the heterogeneity of the crust and to deploy appropriate monitoring instruments at "sensitive sites", such as along faults or weak zones and especially on the hanging walls in case of thrust faults, where crustal strain may concentrate. At the same time, models used to interpret data need to account for this geological heterogeneity. In view of rarity of destructive earthquakes in any given region and for the purpose of understanding background variations, it is important to maintain long-term monitoring and data collection. 


\section{Acknowledgements}

We thank the following reviewers for their help in evaluating the submitted manuscripts: P.F. Bari, Y. Chi, G. De Luca, B. Delbridge, Y. Fialko, P. Fulton, Z. Geballe, S. Hao, G.C.P. King, Y. Kitagawa, N. Koizumi, G. Lai, X. Lei, K.F. Ma, G. Li, C. Mohr, Y.L. Rebetsky, Z. Shi, R.P. Singh, Y. Taran, C.-Y. Wang, G. Wang, L. Xue, S. Yabe, R. Yan, L. Yi, Y. Zhang, X. Zhou.

\section{REFERENCES}

Coussy, O. (2004). Poromechanics. Hoboken: Wiley.

Dubois, C. (1995). Gas geochemistry. Northwood: Science Reviews.

Geller, R. J., Jackson, D. D., Kagan, Y. Y., \& Mulargia, F. (1997). Earthquakes cannot be predicted. Science, 275, 1616.

King, C.-Y. (1980). Geochemical measurements pertinent to earthquake prediction. Journal of Geophysical Research, 85, 3051.

King, C.-Y. (1981). A special collection of reports on earthquake prediction: Hydrologic and geochemical studies. Geophysical Research Letters, 8, 421-424.

King, C.-Y. (1984) Earthquake hydrology and chemistry. Pure and Applied Geophysics, 122, 141-142.

King, C.-Y. (1986). Preface to gas geochemistry of volcanism, earthquakes, resource exploration, and Earth's interior. Journal of Geophysical Research, 91, 12157.

King, C. -Y. (2018). Characteristics of a sensitive well showing pre-earthquake water-level changes. Pure and Applied Geophysics https://doi.org/10.1007/s00024-018-1855-4.

King, C. -Y., \& Chia, Y. (2017). Anomalous streamflow and groundwater-level changes before the 1999 M7.6 Chi-Chi earthquake in Taiwan: Possible mechanisms. Pure and Applied Geophysics. https://doi.org/10.1007/s00024-017-1737-1

Liu, C. -Y., Chia, Y., Chuang, P. -Y., Wang, C. -Y, Ge, S., \& Teng, M. -H. (2017). Streamflow changes in the vicinity of seismogenic fault after the 1999 Chi-Chi earthquake. Pure and Applied Geophysics. https://doi.org/10.1007/s00024-017-1670-3

Ma, Y., Wang, G., \& Tao, Y. (2017). Hydrological changes induced by distant earthquakes at the Lujiang well in Anhui, China. Pure and Applied Geophysics. https://doi.org/10.1007/ s00024-017-1710-z

Molchan, G. M. (1990). Strategies in strong earthquake prediction. Physics of the Earth and Planetary Interiors, 61, 84-98.
Perez, N. M., Gurrieri, S., King, C.-Y., \& McGee, K. (2006). Introduction to terrestrial fluids, earthquakes and volcanoes: The Hiroshi Wakita Volume I. Pure and Applied Geophysics, 163, 629-914.

Perez, N. M., Gurrieri, S., King, C.-Y., \& McGee, K. (2007). Introduction to terrestrial fluids, earthquakes and volcanoes: The Hiroshi Wakita Volume II. Pure and Applied Geophysics, 164, 2373-2571.

Perez, N. M., Gurrieri, S., King, C.-Y., \& McGee, K. (2008). Introduction to terrestrial fluids, earthquakes and volcanoes: The Hiroshi Wakita Volume III. Pure and Applied Geophysics, 165, 1-180.

Rebetsky, Yu L. (2009). Estimation of stress values in the method of cataclastic analysis of shear fractures. Doklady Earth Sciences, 428, 1202-1207.

Ren, Y., Ma, J., Liu, P., \& Chen, S. (2017). Experimental study of thermal field evolution in the short-impending stage before earthquakes. Pure and Applied Geophysics. https://doi.org/10. 1007/s00024-017-1626-7

Sarychikhina, O., Glowacka, E., González, R. V., \& Arreazol, M. F. (2018). Analysis and interpretation of earthquake-related groundwater response and ground deformation: A case study of May 2006 seismic sequence in the Mexicali Valley, Baja California, Mexico. Pure and Applied Geophysics. https://doi.org/10. 1007/s00024-018-1925-7.

Segall, P. (2010). Earthquake and volcano deformation. Princeton: Princeton University Press.

Shi, Z., Wang, G., Liu, C., \& Che, Y. (2017). Tectonically induced anomalies without large earthquake occurrences. Pure and Applied Geophysics. https://doi.org/10.1007/s00024-017-1596-9

Sun, X., Xiang, Y., Shi, Z., \& Wang, B. (2017). Preseismic changes of water temperature in the Yushu well, western China. Pure and Applied Geophysics. https://doi.org/10.1007/s00024-017-1579-x

Wang, H. F. (2000). Theory of linear poroelasticity. Princeton: Princeton University Press.

Wang, C.-Y., \& Manga, M. (2010). Earthquakes and water. New York: Springer.

Wang, K., Rebetsky, Y., Ma, S., Feng, X., \& Liu, G. (2018). Background stress state before the 2008 Wenchuan Earthquake and the dynamics of the Longmen Shan thrust belt. Pure and Applied Geophysics https://doi.org/10.1007/s00024-018-1800-6.

Wang, B., Zhu, C., Yan, L., \& Yao, Y. (2018). Hydrogeological and geochemical observations for earthquake prediction research in China: A brief overview. Pure and Applied Geophysics. https://doi.org/10.1007/s00024-018-1885-y.

Zhang, S., Shi, Z., Wang, G., \& Zhang, Z. (2017). Quantitative assessment of the mechanisms of earthquake-induced groundwater level changes in the MP well, Three Gorges area. Pure and Applied Geophysics. https://doi.org/10.1007/s00024-017-1643-6 